\title{
Initial Interest, Goals, and Changes in CLASS Scores in Introductory Physics for Life Sciences
}

\author{
Catherine H. Crouch*, Panchompoo Wisittanawat*† and K. Ann Renninger $\dagger$ \\ *Department of Physics, Swarthmore College, 500 College Ave, Swarthmore, PA 19081 \\ $\dagger$ Department of Educational Studies, Swarthmore College, 500 College Ave, Swarthmore, PA 19081
}

\begin{abstract}
To examine the effect of extensive life science applications on student attitudes to learning physics, we analyzed CLASS data from life science students in introductory physics. We compare the same students' responses from the first semester, taught with a standard syllabus, to the second semester, taught with extensive life science applications (IPLS). Although first semester responses become less favorable (pre to post), IPLS responses show an increase in favorable and a decrease in unfavorable responses. This is noteworthy because improvement is rarely observed without direct attention to attitudes/beliefs, and suggests IPLS courses are one possible approach to improving attitudes. Finally, we analyzed CLASS responses by gender, major, students' stated goals in taking physics, and initial interest in physics; initial interest was determined from CLASS items chosen based on the Four-Phase Model of Interest Development. Most notably, we find that in the IPLS course, students identified as having low interest initially had the greatest gains.
\end{abstract}

Keywords: CLASS, physics for life sciences, IPLS, interest development

PACS: 01.40.G-, 01.40.gb, 01.40.Fk

\section{INTRODUCTION}

As the understanding of the physical mechanisms of biology increases, and as physics-based technological tools permeate both biological research and clinical medicine, national reports from the life science (e.g. BIO 2010) [1] and medical (e.g. Scientific Foundations for Future Physicians) [2] communities stress the value of a deep understanding of the physical sciences and a high level of problem solving and mathematical skills. Simultaneously, there has been a widespread effort to reform the introductory physics course for life science students (hereafter IPLS) to better match these goals. [3]

Organizing IPLS courses around rich biological examples is a centerpiece of many course reforms, both to motivate students to learn physics and to give students the opportunity to apply physics to the complex biological situations they need to learn to analyze. As one of us and Heller described, [4] the cognitive apprenticeship model of pedagogy stresses the importance of embedding learning in a context meaningful to the student. [5] For students pursuing biology or medicine, this implies that required introductory physics course work should anchor physics principles in meaningful biological contexts.

Research suggests that supporting students to make meaningful connections to the content to be learned enables interest to develop, [6] and, in turn, interest enhances attention, goal setting, and learning strategies. [7] For example, research by Häussler and
Hoffman demonstrated that teaching physical science using life science contexts led to improved learning for students who were interested in those contexts. [8] Finally, a preliminary intervention study by Engle and coworkers suggests that combining a context meaningful to the student with "expansive framing," in which the instructor emphasizes that the material being learned will be valuable to the student outside the classroom, makes a difference in learning. [9]

Anecdotally, we (and others) have also observed that IPLS students are enthusiastic about the integral life science examples. We set out to determine whether including these examples also leads to improvements in student interest in, attitudes to, and beliefs about learning physics, as measured by both the Colorado Learning About Science Survey (CLASS) [10] and a survey we designed to probe the development of students' interest. [7] Here we report the results of our CLASS study, together with those course evaluation responses that help interpret those results; we present the results of the interest survey separately. [11]

\section{STUDY DESIGN}

Swarthmore College formerly offered a year-long calculus-based introductory physics course that was taken by engineering, chemistry, and biochemistry majors, and pre-medical students. When the IPLS reform was initiated, all students continued to take the standard first semester course (Physics 3), and a new IPLS second semester course (Physics 4L) was offered as an alternative to the standard second semester. 
Engineering students continued to take the standard second semester while biochemistry, some chemistry, and pre-medical students took the IPLS course.

We therefore have the opportunity to do a withinstudent comparison, comparing students' CLASS responses from the standard first semester to IPLS second semester. We examine matched data from two academic years (Year 1: $N=75$ [28 male, 47 female]; Year 2: $N=38$ [13 male, 25 female]). Enrollment was twice as large in Year 1 because at the time of course enrollment it was not certain that the IPLS course would be offered in Year 2; consequently, we draw our primary conclusions from the Year 1 data, and discuss the consistency of Year 1 with the Year 2 data.

In addition to the CLASS survey, we separately obtained demographic information about the students: class year, major, and their reasons for enrolling in the course. This survey was administered separately to minimize stereotype threat effects. [12] Finally we tested students with the Brief Electricity and Magnetism Assessment (BEMA) both pre and post. The BEMA and CLASS were administered online through a secure course website and homework credit was given for completion; demographic information was obtained separately.

The IPLS course and the standard first semester course were taught by different instructors (CHC taught the IPLS course and a colleague taught the standard course). Both courses were taught with three hours of Peer Instruction (PI) lecture, [13] although the instructor for the IPLS course was more experienced with using PI. Both had a weekly three-hour laboratory in which the labs were loosely informed by PER-based curricula. Informal (and optional) evening meetings to work on the weekly problem sets were facilitated by peer tutors; there was neither a scheduled recitation nor a required additional time for formal group problem solving.

\section{METHODS OF ANALYSIS}

We analyzed the CLASS responses in two complementary ways. We used the established method of collapsing the responses to a three-point scale (favorable, unfavorable, neutral), and then determining percent favorable and unfavorable changes from pre to post, both overall and in eight categories. [10] This approach gives two sub-scores for each category. While this gives a great deal of rich information, it can be difficult to interpret clearly, such as when both favorable and unfavorable responses increase, or both decrease.

We therefore also recoded negative statements in the reverse direction and calculated mean changes in scores on the five-point scale. This approach has the advantage of providing a single score and also facilitates analysis.

Both methods of analysis were examined for correlations with student characteristics (demographic data, goals for taking course, and BEMA scores). To investigate the role of interest, we developed a metric for initial interest in physics [14] using twelve items ${ }^{1}$ from the CLASS pre-survey: the six items from the CLASS Personal Interest category used to assess feelings and value, and six other items that assess the knowledge components of interest, providing an assessment of interest as a developmental motivational variable, used here to identify initial interest in physics [7] We then divided the class into high (top quartile), medium (two middle quartiles), and low (bottom quartile) level of initial interest.

\section{RESULTS}

Consistent with the literature [10], we find that, on average, students' attitudes hold steady or improve during the IPLS second semester, while students' attitudes become less expert-like during the standard first semester. Table 1 displays the results of the favorable- unfavorable analysis, along with the means on the five-point scale, for all students in each semester, and for the matched student population who took both semesters. The two approaches to analysis give consistent results, although they differ in the level of statistical significance. We observe the same trends in both years.

\section{Demographics and Background}

We examined several demographic factors for influence on changes in CLASS scores: gender, math background (as measured by college math courses taken prior to/concurrently with physics), major (life science or not), and self-reported goals for the IPLS course. Using two-way repeated measure ANOVAs, no effects of major or math background or incoming knowledge as measured by the BEMA pre score were found with $p<0.05$.

Although female students displayed more negative initial attitudes than males on two of the problemsolving categories (Confidence and General), there was no effect of gender on changes either semester. Although this is encouraging, as others have reported an increasing gender gap from pre to post in CLASS scores, [15] it is not clear to what to attribute this as it occurs in both semesters with different instructors.

\footnotetext{
${ }^{1}$ Items 3, 6, 11, 14, 20, 25, 28, 30, 32, 37, 40, and 42. The CLASS and its categories are provided in Ref. 10; see Ref. 14, p. 17, for how this interest metric was constructed.
} 
TABLE 1. Pre to post CLASS changes, both changes in $\%$ favorable/unfavorable and mean change on the 5-point scale. "Post to post" changes were calculated as post- $2^{\text {nd }}$ semester (IPLS) - post- $1^{\text {st }}($ standard). $* p<0.05, * * p<0.01, * * * p<0.001$.

\begin{tabular}{|c|c|c|c|c|c|c|c|c|c|c|c|c|c|c|c|}
\hline \multirow{4}{*}{ CLASS Category } & \multicolumn{6}{|c|}{ All students } & \multicolumn{9}{|c|}{ Matched data $(n=37)$} \\
\hline & \multicolumn{3}{|c|}{ Traditional $(n=76)$} & \multicolumn{3}{|c|}{ IPLS $(n=57)$} & \multicolumn{3}{|c|}{ Traditional } & \multicolumn{3}{|c|}{ IPLS } & \multicolumn{3}{|c|}{ IPLS (Post to Post) } \\
\hline & $\%$ & $\%$ & Mean & $\%$ & $\%$ & Mean & $\%$ & $\%$ & Mean & $\%$ & $\%$ & Mean & $\%$ & $\%$ & Mean \\
\hline & Fav & Unfav & Change & Fav & Unfav & Change & Fav & Unfav & Change & Fav & Unfav & Change & Fav & Unfav & Change \\
\hline Overall & $-3.0 *$ & $4.9 * * *$ & $-0.12 * * *$ & 1.4 & -1.3 & 0.03 & -2.1 & $6.2 * *$ & $-0.13 * *$ & 1.4 & -1.9 & 0.02 & 1.6 & $-4.3^{*}$ & $0.09^{*}$ \\
\hline Real World Connec & -4.1 & $6.9^{* *}$ & $-0.19 * *$ & 0.2 & $-6.4^{*}$ & 0.06 & -2.7 & $9.2^{*}$ & -0.17 & -1.6 & $-6.8^{*}$ & 0.01 & -2.9 & $-10.1^{*}$ & 0.11 \\
\hline Personal Interest & $-7.5 * *$ & $9.2 * * *$ & $-0.28 * * *$ & 1.0 & -2.6 & 0.02 & -4.5 & $10.2^{* *}$ & $-0.24 * *$ & 0.9 & -0.0 & -0.05 & -2.1 & -6.2 & 0.06 \\
\hline SenseMaking/Effort & $-8.6 * *$ & $8.3^{* * *}$ & $-0.27 * * *$ & -1.1 & 1.5 & -0.04 & $-8.0^{*}$ & $6.5^{*}$ & $-0.14 * * *$ & 0.0 & -0.1 & -0.03 & -0.2 & -0.3 & -0.01 \\
\hline Concep Connect & -1.3 & 1.7 & -0.05 & 5.2 & -1.6 & 0.08 & -4.4 & 3.9 & 0.01 & 4.5 & -2.7 & 0.07 & 5.8 & -4.8 & $0.17 *$ \\
\hline Appl Concep Underst & 2.6 & 0.3 & 0.02 & $7.3^{* *}$ & -1.5 & $0.11 *$ & 1.2 & 1.5 & -0.17 & 4.1 & -3.0 & 0.08 & 3.3 & -3.0 & $0.12 *$ \\
\hline Prob Solv Genl & -5.1 & $7.4 * *$ & $-0.16^{*}$ & 1.3 & -1.2 & 0.03 & -1.7 & $10.0 * *$ & $-0.18^{*}$ & 3.7 & -3.3 & 0.04 & $8.1^{*}$ & $-6.6 * *$ & $0.16^{*}$ \\
\hline Prob Solv Confid & -5.9 & $6.8^{*}$ & $-0.16^{*}$ & 3.6 & -2.0 & 0.05 & -3.4 & $12.2 * *$ & -0.18 & 6.1 & -4.7 & 0.06 & $12.8^{*}$ & -6.1 & $0.21 *$ \\
\hline Prob Solv Sophist & -5.3 & $8.0^{*}$ & $-0.18^{*}$ & $8.4^{* *}$ & -2.2 & 0.11 & -2.3 & $8.6^{*}$ & -0.15 & 6.0 & -4.4 & 0.07 & $8.8^{*}$ & $-7.7 *$ & $0.20 * *$ \\
\hline
\end{tabular}

\section{Initial Interest and Goals}

The most striking effects were associated with students' initial levels of interest and self-reported goals. In both courses, as shown in Fig. 1, CLASS pre scores overall and in all categories tracked students' initial level of interest. Remarkably, in the IPLS course, we observed that the low initial interest students' CLASS scores increased significantly from pre to post, both overall and in the Real World Connection, Personal Interest, and Problem Solving General categories, as shown in Fig. 2, while the medium interest students' scores remained steady and those of the high interest students declined slightly. (In other categories the three interest groups were less distinguishable.) However, in both years of the study all groups in the standard course declined by similar amounts from pre to post. This suggests that the IPLS course promotes the improvement of students' perceptions of physics for initially low interest students.

Students' goals for the course showed similar effects. We categorized students' statements of their

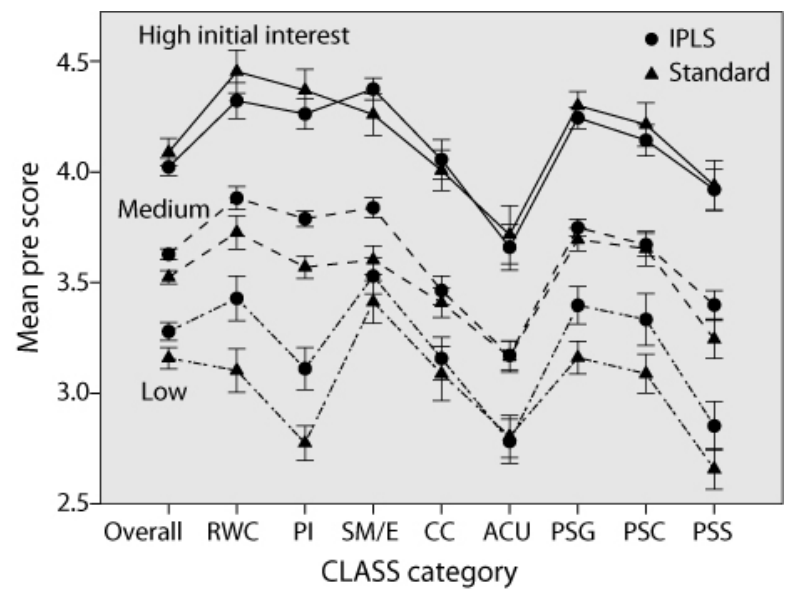

FIGURE 1. Mean CLASS pre-scores (5-point scale, error bar $=$ standard error) by category and initial interest level. Full category names are listed in Table 1. goals in taking the IPLS course as (a) learning the material, (b) meeting a requirement, or (c) both. Students expressing learning goals had the highest initial CLASS scores, followed by those with both goals, and then those whose goals were to meet a requirement. Those students with a requirement goal showed the greatest CLASS gains from pre to post, while scores of those with a learning goal did not change significantly. In most cases those with both goals did not change, but in Sense-Making/Effort their scores declined $(p<0.05)$. Moreover, students with high initial interest were likely to report learning goals, whereas students with low interest were likely to report requirement goals $(p<.05)$.

\section{Course Evaluation}

We asked questions on the IPLS end-of-semester course evaluation that probed students' perception of the utility of the IPLS course and their level of interest. One pair of questions used in both Years 1 and 2 asked students to compare their perception of the utility of the IPLS course at its beginning and end; students

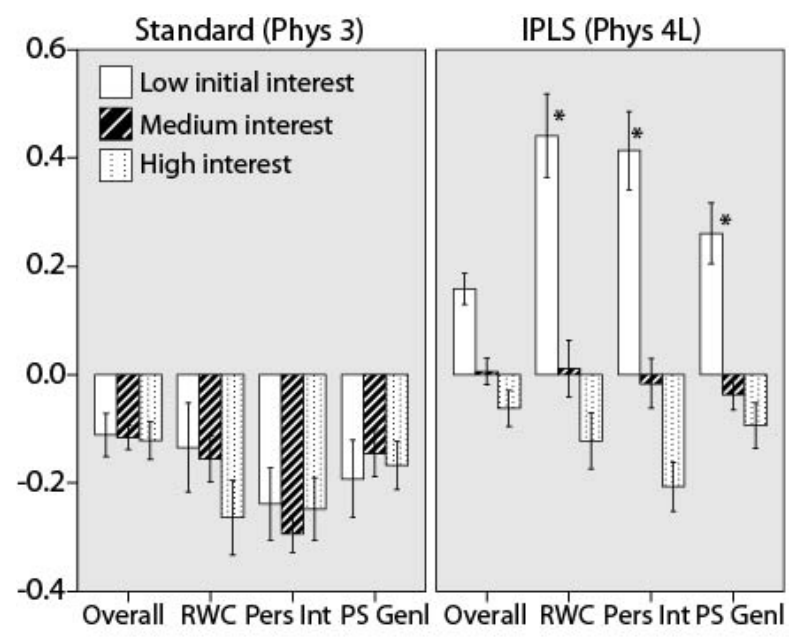

FIGURE 2. Mean changes in CLASS scores (pre to post, 5point scale) by initial interest level. *Significant differences between interest groups $(p<0.05)$. Error bars $=$ standard error. 
indicate that their perception of utility increased ( $p<$ 0.001). In Year 2, additional survey items indicated that students found the course more interesting (average rating $4.50 \pm 0.12,4=$ somewhat more, $5=$ much more) and more useful $(4.33 \pm 0.13)$ than if it had been taught without biological examples. Interest and perceived utility were correlated $(p<0.01)$, as expected based on research on interest and utility. [16]

\section{DISCUSSION AND CONCLUSIONS}

Our findings suggest that the IPLS course, unlike the standard course, supports students with low initial interest and/or requirement goals to develop interest, along with more positive attitudes and beliefs as assessed by the CLASS. These results are consistent with those observed in some other IPLS courses. [4, 17]

Based on course evaluation responses, we propose that positive outcomes on the CLASS during the IPLS semester can be attributed at least in part to the focus on topics and examples most relevant to life science students. This is consistent with findings from Häussler and Hoffman's [8] intervention study, in which students improved in their performance, sense of competence, and self-concept in physics, when physics was taught through contexts that were of interest.

Although previous studies have found that sometimes CLASS scores improve in the second semester even without explicit attention to attitudes/beliefs, [10] the difference in gains reported here suggest that the improvements are related to engaging student interest, with interest defined so as to include its developmental nature. Clearly research is also needed comparing standard to IPLS first semester courses.

Given studies indicating the role of utility as a support for developing meaningful connections to content [16], and others pointing to the relationship between interest and goals, especially in the early phases of interest development, [18] our findings further suggest that the life science content contributes utility and meaning for students to the IPLS course.

Given that high initial interest students showed a modest decline in CLASS scores, it also appears that future work should focus on strategies to maintain or further develop these students' interest. Other studies of the development of interest [19] suggest that high initial interest students could also be engaged by IPLS courses employing more mathematical/technical life science applications that challenge them to extend their present understanding of the life science contexts.

\section{ACKNOWLEDGMENTS}

We thank Carl Grossman and Amy Graves for surveying their Physics 3 students, Ann Ruether for assistance with surveys and data analysis, and the University of Maryland NEXUS group for helpful conversations, particularly for encouraging comparison between the standard and IPLS courses. This work was partly funded by a grant to Swarthmore College from the Howard Hughes Medical Institute through the Precollege/Undergraduate Science Education program.

\section{REFERENCES}

1. BIO2010: Transforming Undergraduate Education for Future Research Biologists, Committee on Undergraduate Biology Education, National Research Council (National Academies Press, 2003).

2. Scientific Foundations for Future Physicians: Report of the HHMI-AAMC Committee (American Association of Medical Colleges, 2009).

3. See for example the programs for sessions "Reforming the Introductory Physics Course for Life Science Students" held at the AAPT national meetings since 2009 (at http://www.aapt.org/AbstractSearch/).

4. C. H. Crouch and K. Heller, "Teaching Physics to Life Science Students," in PER Conference Proceedings 2011, AIP: Melville, NY (2011).

5. A. Collins, J. S. Brown, and A. Holum, American Educator 6, 6-46 (1991).

6. M. Mitchell, J. Ed. Psych. 85, 424-436 (1993).

7. S. Hidi and K. A. Renninger, Ed. Psych., 41 (2), 111-127 (2006).

8. P. Häussler and L. Hoffmann, J. Res. Sci. Teach. 39 (9), 870-888 (2002).

9. R. Engle, P. Nguyen, and A. Mendelson, Instructional Science 39, 603-628 (2011).

10. W. Adams, et al, PRST-PER 2, 010101 (2006).

11. P. Wisittanawat, K. A. Renninger, and C. H. Crouch, submitted to Am. J. Phys. (2013).

12. C. M. Steele, Am. Psych. 52 (6), 613 (1997).

13. C. H. Crouch, J. Watkins, A. P. Fagen, and E. Mazur, "Peer Instruction: Engaging students one-on-one, all at once," in Research-Based Reforms in University Physics, ed. E. F. Redish, College Park: AAPT, 2007.

14. Panchompoo Wisittanawat, "Supporting Interest: Life Science Students' Learning about Physics with Biological Contexts," Honors Thesis, Swarthmore College, 2013.

15. L. E. Kost-Smith, S. J. Pollock, and N. D. Finkelstein, PRST-PER 6 (2), 020112.

16. C. S. Hulleman and J. Harackiewicz, Science 326, 14101412 (2009).

17. Project NEXUS, University of Maryland.

18. J. M. Harackiewicz et al, J. Ed. Psych. 100, 105-122 (2008).

19. K. A. Renninger, "Working with and cultivating interest, self-efficacy, and self-regulation," in D. Preiss \& R. Sternberg (Eds.), Innovations in educational psychology: Perspectives on learning, teaching and human development, pp. 158-195. New York: Springer (2010). 